\title{
ACMG Standards and Guidelines for fragile $X$ testing: a revision to the disease-specific supplements to the Standards and Guidelines for Clinical Genetics Laboratories of the American College of Medical Genetics and Genomics
}

\author{
Kristin G. Monaghan, $\mathrm{PhD}^{1}$, Elaine Lyon, $\mathrm{PhD}^{2}$ and Elaine B. Spector, $\mathrm{PhD}^{3}$
}

\begin{abstract}
Note: This supersedes Technical Standards and Guidelines for Fragile X Testing: The First of a Series of Disease-Specific Supplements to the Standards and Guidelines for Clinical Genetics Laboratories of the American College of Medical Genetics and Genomics (Genetics in Medicine 2001;3(3):200) and Technical Standards and Guidelines for Fragile X Testing: A Revision to the Disease-Specific Supplements to the Standards and Guidelines for Clinical Genetics Laboratories of the American College of Medical Genetics and Genomics (2006).

Disclaimer: These American College of Medical Genetics' Standards and Guidelines are developed primarily as an educational resource for clinical laboratory geneticists to help them provide quality clinical laboratory genetic services. Adherence to these standards and guidelines is voluntary and does not necessarily ensure a successful medical outcome. These Standards and Guidelines should not be considered inclusive of all proper procedures and tests or exclusive of other procedures and tests that are reasonably directed to obtaining the same results. In determining the propriety of any specific procedure or test, the clinical laboratory geneticist should apply his or her own professional judgment to the specific circumstances presented by the individual patient or specimen. Clinical

laboratory geneticists are encouraged to document in the patient's record the rationale for the use of a particular procedure or test, whether or not it is in

conformance with these Standards and Guidelines. They also are advised to take notice of the date any particular guideline was adopted and to consider other relevant medical and scientific information that becomes available after that date. It also would be prudent to consider whether intellectual property interests may restrict the performance of certain tests and other procedures.
\end{abstract}

Molecular genetic testing of the FMR1 gene is commonly performed in clinical laboratories. Mutations in the FMR1 gene are associated with fragile $\mathrm{X}$ syndrome, fragile $\mathrm{X}$ tremor ataxia syndrome, and premature ovarian insufficiency. This document provides updated information regarding FMR1 gene mutations, including prevalence, genotype-phenotype correlation, and mutation nomenclature. Methodological considerations are provided for Southern blot analysis and polymerase chain reaction amplification of the FMR1 gene, includ- ing triplet repeat-primed and methylation-specific polymerase chain reaction. In addition to report elements, examples of laboratory reports for various genotypes are also included.

Genet Med 2013:15(7):575-586

Key Words: FMR1; fragile X syndrome; Southern blot analysis; triplet repeat-primed PCR
The American College of Medical Genetics and Genomics Laboratory Quality Assurance Committee has the mission of maintaining high technical standards for the performance and interpretation of genetic tests. In part, this is accomplished by the publication of the document "ACMG Standards and Guidelines for Clinical Genetics Laboratories," which was published in its second edition in 1999 and is now maintained online (http:// www.acmg.net/StaticContent/SGs/Section_G_2010.pdf). This subcommittee also reviews the outcome of national proficiency testing in the genetics area and may choose to focus on specific diseases or methodologies in response to those results. Accordingly, the subcommittee selected fragile $\mathrm{X}$ syndrome to be the first topic in a series of supplemental sections, recognizing that it is one of the most frequently ordered genetic tests and that it has many alternative methods with different strengths and weaknesses. This document is the second update to the original Standards and Guidelines for Fragile X testing that were published in 2001. It is designed for genetic testing professionals who are already familiar with the disease and the methods of analysis.

\section{FX 1: INTRODUCTION}

Disease-specific statements are intended to augment the current general ACMG Standards and Guidelines for Clinical Genetics Laboratories. Individual laboratories are responsible for meeting the Clinical Laboratory Improvement Amendments/ College of American Pathologists (CAP) quality assurance standards with respect to appropriate sample documentation, assay validation, general proficiency, and quality control measures. 


\section{FX 2: BACKGROUND ON FRAGILE X SYNDROME} FX 2.1: Gene symbol/chromosome locus

FMR1 is the gene symbol recognized by the HUGO gene nomenclature committee (http://www.genenames.org/data/ hgnc_data.php?hgnc_id=3775). The gene was referred to as FXA in the past. The chromosome locus is Xq27.3.

\section{FX 2.2: OMIM number}

The OMIM numbers are as follows: ${ }^{\star} 309550$ (FMR1), 300624 for fragile X mental retardation syndrome (includes fragile $\mathrm{X}$-associated primary ovarian insufficiency), and 300623 for fragile X tremor/ataxia syndrome (FXTAS).

\section{FX 2.3: Brief clinical description}

The features of fragile $\mathrm{X}$ syndrome include specific cognitive deficits and certain characteristic, but nonspecific, physical features and behaviors. Most individuals with the premutation do not show fragile X syndrome-related features; however, some with high repeat sizes ( $>100$ repeats) have been identified with learning difficulties, emotional problems, or even intellectual disability. ${ }^{1}$ Females with premutations (usually $>80$ CGG repeats) are at $\sim 20 \%$ risk for premature ovarian insufficiency (POI). ${ }^{2-7}$ This condition is now referred to as FXPOI. There is no evidence to support an association between high normal and intermediate range $F M R 1$ alleles with a risk of POI. ${ }^{8,9}$ Older males and females with premutations are at risk for FXTAS. ${ }^{10-16}$ FXTAS is a late-onset, progressive development of intention tremor and ataxia often accompanied by progressive cognitive and behavioral difficulties including memory loss, anxiety, reclusive behavior, deficits of executive function, and dementia. The risk for FXTAS is higher in males who carry a premutation as compared with females. The penetrance of FXTAS increases with age and with premutation repeat length. ${ }^{17,18}$ Guidelines to identify patients for whom FXTAS testing is indicated are available. ${ }^{19}$ For more information on these disorders, see the online GeneReviews profile for FMR1-related disorders at http://www. ncbi.nlm.nih.gov/sites/GeneTests/ and the National Fragile X Foundation at http://www.nfxf.org.

\section{FX 2.4: Mode of inheritance}

Inheritance of the FMR1 mutation is X-linked, although the pattern of fragile $\mathrm{X}$ syndrome is complicated due to the characteristics of the unstable repeat sequence mutation. In typical fragile $\mathrm{X}$ families, the mutation is a multistep expansion occurring over one or more generations in a region of CGG repeats in the $5^{\prime}$ untranslated region of the gene. Small expansions (premutations) are not generally associated with cognitive deficits in males and females. Large expansions (full mutations) are penetrant in all males and many females. With extremely rare exceptions, the parent of origin of the expansion to the full mutation is female.

\section{FX 2.5: Gene description/normal gene product}

The gene product is fragile $\mathrm{X}$ mental retardation protein (FMRP), a widely expressed RNA-binding protein. The fragile
$\mathrm{X}$ syndrome is caused by a loss of the FMRP. FMRP is a selective RNA-binding protein that can form a messenger ribonucleoprotein complex that can associate with polysomes. ${ }^{20} \mathrm{FMRP}$ has been shown to behave in vitro as an inhibitor of protein translation. ${ }^{21}$ At the neuroanatomic level, the fragile $\mathrm{X}$ brain differs from normal brain due to the presence of unusually long and thin dendritic spines in the cortical regions. ${ }^{22,23}$ The dendritic spines are the location where excitatory synaptic transmission occurs. FMRP appears to be associated with polyribosomes within dendritic spines of "wild-type" neurons. ${ }^{24}$ From these data, it has been proposed that FMRP is a translation suppressor that regulates protein synthesis locally in dendrites in response to synaptic stimulation signals. ${ }^{25} \mathrm{In}$ the fragile $\mathrm{X}$ brain, translation of certain messages may be exaggerated because the normal inhibition provided by FMRP is absent. ${ }^{26}$

Studies of FMR1 mRNA expression provide evidence that expansion in the premutation range perturbs gene expression and may have pathophysiological consequences, particularly those related to FXTAS and ovarian failure (see section 2.3). Reductions in the amount of FMRP have been found in both lymphocytes and transformed lymphocytes of premutation carriers. ${ }^{27,28}$ Using a highly sensitive fluorescent assay, Kenneson et al. $^{28}$ demonstrated a decrement in FMRP in individuals with expansions only slightly larger than the upper edge of the normal range. The reduction in FMRP is associated with an increase in FMR1 mRNA $^{1,27-29}$ in individuals with premutations. Expansion of the CGG repeats into the premutation range can shift transcription of FMR1 mRNA from the usual, downstream-most start site to upstream sites. The utilization of alternative start sites may be correlated with increased FMR1 mRNA transcription levels. ${ }^{30}$ RNA-mediated toxicity may result in the FXTAS phenotype. ${ }^{31}$

\section{FX 2.6: Mutational mechanism/abnormal gene product}

Fragile X syndrome is caused by the deficiency or absence of FMRP. Theoretically, this can occur through any type of deletion or inactivating mutation, but in more than $99 \%$ of cases, there is an expansion of a segment of CGG repeats in the $5^{\prime}$ untranslated region of FMR1. Large CGG expansions in this region are associated with hypermethylation and inhibition of transcription.

\section{FX 2.7: Listing of mutations}

Mutations at locations other than the CGG repeat have been described. A listing can be found in the Human Gene Mutation Database at http://www.hgmd.cf.ac.uk/ac/index. php. Guidelines for detecting these relatively rare mutations are beyond the scope of this document.

\section{FX 2.8: Prevalence and ethnic association of common mutations \\ FX 2.8.1: Full mutations. The general prevalence of males with a full mutation is estimated as $\sim 1$ in 4,000 . The female prevalence rate is presumed to be approximately one-half of the male rate, or $\sim 1$ in 5,000-8,000..$^{32}$ Two large North American studies using}


anonymized newborns identified a prevalence of 1 in 5,161 US males $^{33}$ and 1 in 6,209 Canadian males. ${ }^{34}$

All major ethnic groups and races appear to be susceptible to expansion of the FMR1 CGG region. ${ }^{32,35}$ An extensive literature review indicated a prevalence of fragile $\mathrm{X}$ syndrome ranging from 1 in 3,717 to 1 in 8,198 among Caucasian males in the general US population. ${ }^{36}$ In another study carried out over 4 years in metropolitan Atlanta, the prevalence of fragile X syndrome was estimated to be 1 in 2,545 among African-American males and 1 in 3,717 among Caucasian males. ${ }^{37}$ However, the prevalence estimate for Caucasian males, determined from this and from other studies, fell within the $95 \%$ confidence interval for African-American males. The prevalence of the fragile $\mathrm{X}$ mutation in an Afro-Caribbean population in the French West Indies was similar (1 in 2,539) to that in the African-American population in Atlanta. ${ }^{38}$ Falik-Zaccai et al. ${ }^{39}$ have suggested that the Tunisian Jewish population is the only other ethnic group to have a higher prevalence of the fragile $\mathrm{X}$ syndrome than the Caucasian population. However, these studies have not been supported by other data. ${ }^{40} \mathrm{~A}$ blinded Taiwanese study estimated the prevalence of fragile $\mathrm{X}$ as 1 in 10,046 males. ${ }^{41}$

Further studies are required to determine if the frequency of the fragile $\mathrm{X}$ syndrome differs in ethnic populations.

FX 2.8.2: Premutations. A study of 2,300 US women identified 1 in 382 as carriers. ${ }^{42}$ In the largest US study to date (of over 119,000 tested), the overall carrier frequency among US females was $1.3 \%$ ( $0.61 \%$ for full mutation and $1.7 \%$ for premutation). ${ }^{43}$

A recent large-scale study of 21,411 anonymous Canadian females (mothers of newborns) identified 1 in 549 as carriers. ${ }^{34}$ Previous screens for the prevalence of premutations (with 55-101 repeats) in French-Canadian women estimated the carrier frequency to be 1 in $259 .{ }^{44} \mathrm{~A}$ subsequent study revealed a 1 in 1,760 prevalence of premutation alleles among Canadian males. ${ }^{45}$

A study from Israel of 36,483 women who requested screening identified 1 in 157 as carriers. ${ }^{46}$ This is consistent with an earlier study of 9,459 women in Israel that found 1 in 152 with alleles having $>54$ repeats. ${ }^{47}$ In the individuals with no family history of the fragile X syndrome, 1 in 166 women were determined to have premutations with a CGG-repeat range of 55-101. This estimate of the premutation carrier frequency is approximately twofold higher than that reported in the studies performed in Canada. Toledano-Alhadef et al..$^{40}$ obtained similar values when studying 14,334 preconceptual or pregnant women in Israel, namely, 1 in 113 women with > 54 CGG repeats. This study excluded women with a family history of mental retardation. In addition, they found that the premutation carriers were well distributed among all the Jewish ethnic groups, in contrast to a previous study. ${ }^{39}$

An Italian study of $\sim 2,000$ mothers and their newborns in the general population found a premutation carrier frequency of 1 in 109 females and 1 in 225 newborn males (56-70 CGG repeats). ${ }^{48} \mathrm{~A}$ fragile $\mathrm{X}$ screen of 10,000 newborn males in Taiwan showed a prevalence of 1 in $1,674 .{ }^{41}$ Therefore, the carrier frequencies vary widely among populations and may be higher than those determined in the French-Canadian population.

Among females with POI and simplex cases of adult males with cerebellar ataxia, the FMR1 premutation is identified in $4-6 \%$ and $2 \%$, respectively. ${ }^{49,50}$

\section{FX 2.9: Special testing considerations}

FX 2.9.1: Sensitivity and specificity. CGG-repeat-expansion full mutations account for $>99 \%$ of cases of fragile X syndrome. Therefore, tests that effectively detect and measure the CGGrepeat region of the FMR1 gene are $>99 \%$ sensitive. Positive results are $100 \%$ specific. There are no known forms of FMRP deficiency that do not map to the FMR1 gene. Fragile X syndrome should not be confused with the unrelated syndrome associated with the FRAXE locus.

FX 2.9.2: Indications for testing. The ACMG and American Congress of Obstetricians and Gynecologists have published recommendations regarding fragile $\mathrm{X}$ testing for diagnostic testing and carrier detection. ${ }^{51-53}$

The identification of a full mutation in a male is considered diagnostic rather than predictive, inasmuch as penetrance of fragile X syndrome is virtually $100 \%$ in males and the age of onset is not variable.

The identification of a full mutation in a female may be diagnostic, but $<50 \%$ of females with full mutations have intellectual disability. They may, however, have some manifestations of the disease such as avoidance personality, mood, or stereotypic disorders. ${ }^{54,55}$ Nonrandom X inactivation may explain the milder phenotype in females, although the extent of symptoms cannot be determined by $\mathrm{X}$-inactivation patterns from diagnostic tests that determine the expansion and methylation in blood.

The identification of a premutation in an asymptomatic male or female undergoing carrier testing (e.g., due to a family history of intellectual disability) is predictive because FXPOI and FXTAS are not fully penetrant and are dependent on both age and allele size.

Population carrier screening and newborn screening for fragile X syndrome are not recommended at this time and should occur only under a research protocol.

FX 2.9.3: Prenatal testing. This test can be used for prenatal diagnosis in cells obtained from amniocentesis and chorionic villus sampling (CVS). Because methylation is not fully established at the time of CVS, the appearance of full mutations examined by a methylation-specific method may vary in CVS as compared with blood and amniocytes. Laboratories offering testing of chorionic villi must be aware of this tissue's unique properties:

- Methylation associated with lyonization is usually not present, and methylation associated with full mutations may or may not be present. ${ }^{56}$ In the past, the hypomethylated status of this locus in this tissue had been thought of as a limitation or possible source of confusion. However, because it is unwarranted to use methylation status or 
X-inactivation for phenotypic prediction of a full mutation, the possible hypomethylation of this tissue is no disadvantage, provided that the tissue-specific basis of the hypomethylation is understood..$^{56,57}$ It is an acceptable option to omit methylation analysis entirely when testing CVS specimens. In the minor fraction of CVS cases with a result that is ambiguous between a large premutation and a small full mutation by size criteria alone, a follow-up amniocentesis may be required;

- The degree of somatic variation in a full mutation "smear" has a wider range of possibilities than is typically seen in blood specimens, from very limited to extraordinarily diffuse;

- Mosaicism between trophoblasts and somatic cells is theoretically possible. For this reason, when CVS results indicate a premutation, follow-up amniocentesis has been suggested to rule out mosaicism for a full mutation. However, there has been no known occurrence of this type of mosaicism.

\section{FX 2.10: Nomenclature}

The use of standard nomenclature is important for the accurate communication of results to health-care providers and is recommended by the $\mathrm{ACMG}^{58}$ and $\mathrm{CAP}^{59}$ According to Human Genome Variation Society recommendations regarding the nomenclature for short sequence repeats, the designation for the FMR1 triplet repeat (based on the coding DNA reference sequence, NM_002024.5) is c.-129CGG[X]. The start of the variable repeat is specified by -129 , and CGG indicates the sequence of the repeat unit. The number of triplet repeats present is specified by X. If the exact size of the repeat cannot be determined (e.g., full mutations sized by Southern blot analysis), then the square brackets are replaced by parenthesis, (X), to signify uncertainties. ${ }^{60}$ Current Human Genome Variation Society recommendations do not address nomenclature for nucleotide repeat mutations with size mosaicism.

Standard nomenclature is recommended, although laboratorians and clinicians may continue to use common mutation nomenclature. Therefore, to avoid confusion, it is acceptable to describe a mutation using standard nomenclature followed by the common name in parentheses or to use the common name in one section of the report (e.g., results) and the standard name in another section (e.g., description of methods or interpretation).

\section{FX 3: GUIDELINES}

\section{FX 3.1: Definition of normal and mutation categories}

There are four allelic forms of the gene: normal, intermediate, premutation, and full mutation. The associated number of CGGs for each can be defined on the basis of our current information to date. It must, however, be recognized that the borders of each definition may change with increased empirical data and research.

FX 3.1.1: Normal alleles. Normal alleles have a range of $\sim 5$ to $\sim 44$ repeats. The most common repeat length is 29 or 30 CGG repeats. Normal alleles have no meiotic or mitotic instability.
FX 3.1.1.1: In stable, normal alleles, the CGG region is interrupted by an AGG triplet after every 9 or 10 CGG repeats. The AGG triplets are thought to anchor the region during replication and prevent strand slippage. Direct testing for the AGG triplets is available clinically, although it is not routinely performed and its clinical usefulness is yet to be determined. It may help predict risk of expansions from premutations of $<100$ repeats. ${ }^{61}$

FX 3.1.2: Intermediate (gray zone, inconclusive, borderline). The range from $\sim 45$ to $\sim 54$ repeats is intermediate (also referred to gray zone, inconclusive, or borderline). Alleles in this range can be considered normal in the sense that such alleles are not associated with fragile $\mathrm{X}$ syndrome and have not been observed to expand to a full mutation in one generation. Although earlier studies suggested an association between alleles in this size range and FXPOI, larger subsequent studies did not support these initial findings. ${ }^{8,9}$ A small number of patients meeting the criteria for FXTAS with FMR1 intermediate alleles have been described, ${ }^{62}$ although larger studies are needed to determine the significance of this finding.

Minor increases and decreases in repeat number can occur when alleles of this size are passed on, but there is no measurable risk of a child with fragile $\mathrm{X}$ syndrome in the next generation. Alleles of this size may be associated with fragile X syndrome in future generations or in distant relatives. Alleles in this range can be referred to as premutations if they are confirmed by family studies to be traceable to a known full mutation or unambiguous premutation. A gray-zone allele of 52 repeats was reported to expand to a premutation allele of 56 repeats in one generation, which subsequently expanded to a full mutation allele in the next generation. ${ }^{63}$ Testing at-risk relatives of individuals with an intermediate allele may determine the stability of the allele in the family. However, the rate of expansions of intermediate alleles is not well understood.

FX 3.1.3: Premutation. Premutation alleles range from $\sim 55$ to $\sim 200$ repeats. These alleles are long repeat tracks that are unstably transmitted from parent to child. Expansions from the premutation size range to the full mutation typically occur during maternal transmission. Due to the possibility of somatic mosaicism, careful examination for mosaicism into the full mutation range is recommended when a premutation is detected. FMR1 alleles in the premutation size range are not hypermethylated and are not associated with fragile $\mathrm{X}$ syndrome. Although males and females with premutations and manifestations of some symptoms of fragile $\mathrm{X}$ syndrome have been reported, further studies are needed. ${ }^{64}$ Women with alleles in this range are considered to be at risk for having affected children. ${ }^{65-67}$ The smallest FMR1 premutation allele reported to expand to a full mutation in a single generation is 56 repeats. ${ }^{63}$ Females who carry an FMR1 premutation should be offered prenatal diagnosis for all pregnancies. Some clinicians may offer prenatal diagnosis to women whose reproductive partner carries a premutation as well. All at-risk family members of 
known carriers should be offered testing to determine their status.

FX 3.1.3.1: The upper limit of premutations is sometimes said to be $\sim 230$. In fact, both numbers (200 and 230) are rough estimates derived from Southern blots in which large premutations were measured with increases of 0.5 to $0.6 \mathrm{~kb}$, implying $\sim 170$ to 200 more triplet repeats than normal.

FX 3.1.4: Full mutations. Full mutations have more than 200-230 repeats, typically several hundred to several thousand repeats. There is usually broad somatic variation within each patient. Hypermethylation is typically present on most or all copies, with the exception of DNA extracted from CVS (see section 2.9.3).

FX 3.1.5: Mosaicism. Mosaicism due to de novo somatic mutations does not occur at the FMR1 CGG-repeat region, but size mosaics and methylation mosaics have been observed. ${ }^{68-71}$ When mosaicism is present, tissue-specific differences can be seen. Individuals with size or methylation mosaicism may be higher functioning than individuals with completely methylated full mutations.

FX 3.1.5.1: Size mosaics. This term refers to an individual with subpopulations of full mutations, which are methylated, and premutations, which are unmethylated. Occasionally, there also may be minor subpopulations with near-normal or normal length. For this reason, care must be taken to examine for larger alleles when a normal or gray-zone allele is detected using standard PCR methods.

FX 3.1.5.2: Methylation mosaics. This term refers to individuals with an FMR1 allele in the full mutation size range, with subpopulations of cells containing an unmethylated full mutation and other populations of cells containing a methylated full mutation.

\section{FX 3.2: Methodological considerations}

All general guidelines for Southern blot analysis and PCR in the ACMG Standards and Guidelines for Clinical Genetics Laboratories apply (http://www.acmg.net). The following additional details are specific for fragile X. For this test, there are many valid methods with different strengths and weaknesses. Laboratories will likely need to use more than one method because no single method can characterize all aspects of the FMR1 full mutation, and precision in determining allele size varies between PCR and Southern blot analysis. For mosaic samples spanning the premutation and full mutation ranges, traditional PCR may amplify the premutation population but not the subpopulation with the full mutation. The expected phenotype for an individual with a premutation versus mosaicism for a premutation and full mutation is very different. Therefore, not detecting the full mutation would result in a different risk assessment for fragile X, FXTAS and FXPOI. ${ }^{51}$ For this reason, the ACMG policy statement recommends that Southern blot analysis always be performed along with traditional PCR, even if a premutation allele is identified by traditional PCR.
However, newer repeat-primed PCR methods or methylation PCR eliminate the need to perform Southern blot analysis on every sample (see section 3.2.2.10).

\section{FX 3.2.1: Southern blot analysis}

FX 3.2.1.1: Probe and restriction site combinations. Table 1 describes several single- and double-enzyme options that are commonly used and several probes that are available. ${ }^{72-75}$ Other restriction enzymes and probes can be used, if equivalence is demonstrated. Probes can be sustained in plasmid DNA and isolated using a plasmid preparation procedure, they can be prepared by PCR amplification, or they can be purchased commercially.

FX 3.2.1.2: In general, when using the StB12.3 probe, small premutations are more easily detected when the normal fragment is small and/or electrophoretic migration is long, whereas large/diffuse full mutations are more easily detected when the normal fragment is large and/or electrophoretic migration is short.

FX 3.2.1.3: Controls should be included to confirm the proper choice and activity of restriction enzymes and probe. They should ideally represent the more difficult-to-recognize genotypes. To verify digestion and hybridization parameters, a normal control will suffice. However, in fragile X blot analyses, the abnormal controls are extremely important because they provide quality control on the resolution of small premutations and the detectability of diffuse smears. Characterized reference material possessing specific FMR1 premutation CGG-repeat sizes may be obtained from the CDC Genetic Testing Reference Materials Coordination Program ${ }^{76}$ through the Coriell Institute for Medical Research. ${ }^{77}$

FX 3.2.1.4: For female patients, it should be noted that the degree of separation between two differently sized normal alleles could appear identical with that between a normal and a premutation allele (e.g., 20 and 44 repeats vs. 35 and 59 repeats). A Southern blot analysis with superior resolution and appropriate size standards or controls is required to distinguish between these possibilities (Figure 1). Alternatively, most PCRbased methods can provide the required resolution. Similar considerations apply to detection of premutation alleles in normal transmitting males.

FX 3.2.1.5: Because full mutations can be extremely diffuse and faint, signal to noise ratios must be very good. Laboratories are advised to be aware of the many different

Table 1 Probe and restriction site combinations

\begin{tabular}{lcc}
$\begin{array}{l}\text { Primary } \\
\text { restriction sites } \\
\text { and normal length }\end{array}$ & $\begin{array}{c}\text { Optional internal } \\
\text { methyl-sensitive } \\
\text { sites }\end{array}$ & $\begin{array}{c}\text { Probes and } \\
\text { references }\end{array}$ \\
\hline EcoRI, $5.2 \mathrm{~kb}$ & Eagl, BssHI, Nrul, etc. & $\begin{array}{c}\text { StB12.3 (ref. 72), } \\
\text { pE5.1 (ref. 73) }\end{array}$ \\
HindIII, $5.4 \mathrm{~kb}$ & Ox1.9 (ref. 74) & $\begin{array}{c}\text { Bg/ll, 12 kb } \\
\text { pfxa3 (ref. 75), } \\
\text { Pstl, 1.0 kb }\end{array}$ \\
& NA & Ox0.55 (ref. 74)
\end{tabular}

NA, not appropriate. 


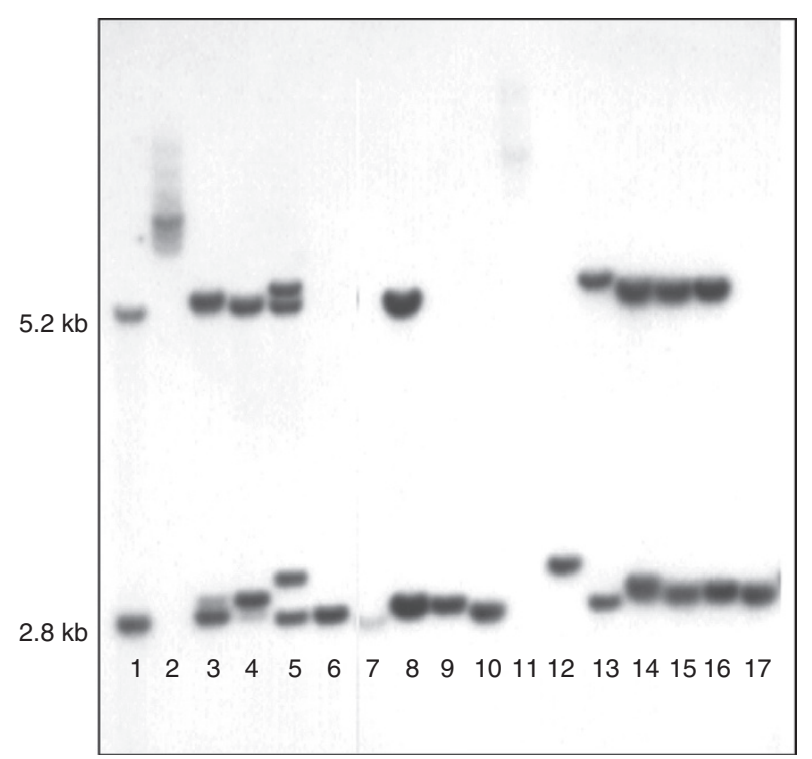

Figure 1 Southern blot using EcoRI and Eagl digestion, probed with StB12.3, using extended electrophoresis to illustrate several subtle specimen types. 1: Normal female; 2 : full-mutation male, note the combination of a predominant band with a diffuse smear; 3 : female with 28 and 52 repeats, with the smaller allele predominantly active; 4: female with 26 and 52 repeats, with the larger allele predominantly active; 5: female with 18 and $\sim 80$ repeats, with equal X-inactivation; 6: normal male; 7: normal male, underloaded and smiling due to DNA degradation (the apparent line between lanes 6 and 7 is a photographic artifact); 8: normal female; 9: normal male; 10: normal male; 11: affected male, underloaded and very diffuse; 12: premutation male; 13: female with 20 and 70 repeats, with the smaller allele virtually exclusively active (the only evidence of abnormality is the slow migration of the " $5.2 \mathrm{~kb}$ " band); 14: female with 27 and 42 repeats, with the larger allele somewhat more active; 15-17: unremarkable normal females and male. Figure provided by Genetics \& IVF Institute. Reprinted from ref. 101.

appearances of full mutations. Full mutations are not likely to be overlooked in males, inasmuch as the normal signal will be absent (or light, in size mosaics), but full mutations can be easily missed in females if the background is poor. Skewed X-inactivation may also present problems in the use of Southern blot analyses performed with methylationsensitive restriction enzymes in the detection of females with premutations or full mutations.

FX 3.2.1.6: Migration distances should be interpreted using a standard ladder such as lambda Hind III fragments or a set of carefully chosen, independently tested human references.

FX 3.2.1.7: The following guidelines refer to methylation analysis using two different restriction enzymes, one of which is methylation sensitive.

$F X$ 3.2.1.7.1: In DNA extracted from tissues other than chorionic villi, methylation analysis reveals the degree of hypermethylation in full mutations and shows the distribution of X-inactivation in any female with two distinguishable alleles. Southern blot analysis with the addition of methylationsensitive enzyme digestion can:
- Help discriminate between premutations and full mutations for the rare alleles that fall near the boundary (i.e., around 200 repeats); and

- Detect rare individuals who are methylation mosaics.

FX 3.2.1.7.2: In DNA extracted from tissues other than chorionic villi, the results of routine methylation analysis and PCR are sometimes confounded by an abnormal karyotype such as $45, \mathrm{X}$ or $47, \mathrm{XXY}$. Individuals with testicular feminization (XY females) will have a male methylation pattern. In these cases, gender should be confirmed. Interpretation of results should take the individual's karyotype into account, when it is available to the molecular laboratory.

FX 3.2.1.7.3: In DNA extracted from tissues other than chorionic villi, methylation analysis increases the difficulty of detecting females with small premutations who have highly skewed X-inactivation. Double digestion with a methylsensitive restriction enzyme causes the signal from each allele in a female to be split into active and inactive bands, forming four bands in a carrier female. When $\mathrm{X}$-inactivation is balanced in a carrier, the two active bands are readily seen, although the two inactive bands may comigrate. However, if $\mathrm{X}$-inactivation is heavily skewed, there will be only two visible bands. This is particularly challenging when the premutation is predominantly inactive because then it appears only in the upper region of the gel, where resolution is considerably poorer. For an example of a carrier with extremely skewed X-inactivation, see lane 13 of Figure 1. Lanes 3 and 4 show two females with oppositely skewed X-inactivation. The above data are true for the use of the StB 12.1 probe. Use of other probes such as pE5.1 will yield an additional small control band.

FX 3.2.1.7.4: FMR1 methylation status should not be used to predict severity in fetal or newborn cases, regardless of whether the DNA was extracted from amniocytes, chorionic villi, or blood.

FX 3.2.1.7.5: In DNA extracted from chorionic villi, the FMR1 region usually does not have methylation associated with $\mathrm{X}$-inactivation, and it may or may not have hypermethylation associated with full mutations if the CVS procedure was performed before 12.5 weeks gestation. ${ }^{56}$ When testing DNA extracted from chorionic villi, methylation analysis is optional. Incidentally, methylation analysis before 12.5 weeks gestation can serendipitously alert a laboratory to maternal cell contamination in chorionic villus specimens inasmuch as methylation associated with $\mathrm{X}$-inactivation is usually not present at this locus in tissue obtained via CVS; a strong normal inactive band can be a sign of possible maternal cell contamination. Other explanations for such a band include $\mathrm{X}$-inactivation in some fetal cells or incomplete digestion. Further investigation would be called for.

\section{FX 3.2.2: $P C R$ methods}

FX 3.2.2.1: Several sets of primers, PCR conditions, and methods of separation and detection have been published. ${ }^{78-81}$ Other primers and methods can be used if equivalence is 
demonstrated. A particular region to be aware of in primer design is the deletional hotspot. ${ }^{82}$ PCR can be performed using ${ }^{32} \mathrm{P}$ and electrophoresis on an acrylamide gel, or more commonly incorporating a fluorescently labeled primer followed by capillary electrophoresis (CE).

FX 3.2.2.2: Regardless of the locus, any PCR can theoretically fail to detect an allele if there is a polymorphism at the primerbinding site. There are no known polymorphisms that would affect any of the commonly used primers.

FX 3.2.2.3: Patient amplicon sizes should be determined using a size standard. For CE, a standard fluorescent-labeled size marker can be used. For acrylamide gels, a standard ladder, such as an M13 sequencing reaction or a set of carefully chosen, independently tested human references, can be used.

FX 3.2.2.4: Controls representing the genotypes to be distinguished should be used for each run. Refer to section 3.2.1.3 for a discussion of reference materials. The upper limit of allele size that can be successfully detected should be known, and a control corresponding to that size should be included in each run. Laboratories should confirm the size of their control DNA by sequencing (if possible) or by using verified reference materials.

FX 3.2.2.5: Amplification of CG-rich regions is difficult, and special conditions are required. The difficulty increases with increasing numbers of CGG repeats; therefore, many PCR strategies do not attempt to detect large alleles. In such a system, it is not possible to tell the difference between a female who is homozygous for a normal allele and one who has a large nonamplifiable second allele. Similarly, patients who are mosaics for premutations and full mutations will appear to have only premutations.

FX 3.2.2.6: When a PCR strategy is capable of detecting large alleles, amplification nevertheless may favor the smaller allele in any specimen with multiple alleles, i.e., females and mosaics.

Such methods should be validated with carrier females and mosaics, in addition to males. Because of disproportionate amplification, PCR is not reliable for determining the ratio of different species in a mosaic individual.

FX 3.2.2.7: In PCR amplification of samples from females and mosaics, heteroduplexes can form. If denaturing polyacrylamide gel electrophoresis is used, conditions must be sufficiently denaturing to avoid heteroduplex artifact. If nondenaturing polyacrylamide gel electrophoresis is used, steps must be taken to distinguish between heteroduplexes and true abnormal alleles.

FX 3.2.2.8: Basic PCR amplification is not affected by methylation. Although PCR tests specifically modified to detect methylation status have been described, ${ }^{83,84}$ the original PCR strategies that have been in use for many years are completely independent of methylation.

FX 3.2.2.9: When a PCR strategy is used to detect full mutations, the presence of a deletion hotspot in the CGGrepeat region should be noted. ${ }^{82}$ Primers located within the deletion hotspot may result in failure to detect the expanded allele. Primers located upstream of the deletion hotspot may result in apparent size mosaicism.

\section{FX 3.2.2.10: Triplet repeat-primed PCR}

FX 3.2.2.10.1: Triplet repeat-primed PCR (TRP PCR) allows rapid detection of PCR products formed by a chimeric primer binding inside a triplet-repeat region. In TRP PCR for fragile $\mathrm{X}$, one primer is anchored completely outside of the CGGrepeat region, whereas the other overlaps the CGG repeat and the adjacent nonrepeated sequence. A third primer can be anchored outside of the CGG region that, when paired with the opposite anchored primer, will amplify "over" the CGG repeat. This will increase the amount of full-length product from the largest CGG-repeat allele and in some assays enables accurate sizing of alleles up to 200 CGG repeats. From the chimeric primer annealing at each CGG repeat, multiple amplicons are made, forming products each with a length differing by three bases. A number of reports have been published describing TRP PCR for fragile X..$^{85-89}$

FX 3.2.2.10.2: Although products can be separated by ethidium-stained agarose gels to detect "smears," combining TRP PCR with single-base-resolution fragment analysis, the "smear" on a lower-resolution agarose gel becomes characteristic "stutters" or "ladders" that are easily visualized. The stuttering will end at the allele with the greatest number of CGG repeats. An increase of this product can be seen, particularly if the third primer is used. For alleles with $>200$ repeats, a "compression" product can be seen, which can be used as a marker for an allele with $>200$ repeats, although the fragment cannot be sized (Figure 2). If a third primer is used, full mutations appear as a compression (or compacted) product. These are seen by CE as a compacted product of $\sim 200$ CGG repeats, thereby indicating a full mutation (Figure 3).

FX 3.2.2.10.3: PCR followed by $\mathrm{CE}$ at a single-base resolution has a high analytical sensitivity and specificity for detecting expanded alleles. A threshold can be set to distinguish premutation and full mutation (and intermediate, if desired) alleles from normal alleles. If no expansion is detected, no further testing is necessary. Alleles with a stuttering pattern past a threshold and consistent with an expansion can be tested further to determine methylation (by Southern blot analysis or methylation-sensitive TRP PCR) or determine size by traditional PCR and/or Southern blot analysis. Therefore, the simple yes/no answer for the presence of expansions can eliminate the need for Southern blot analysis in samples with a normal-sized and intermediate-sized FMR1 allele(s).

FX 3.2.2.10.4: TRP PCR resolves the challenges associated with apparent homozygous females, because the normal allele will not outcompete the expanded allele.

The increased sensitivity of the TRP PCR assay also resolves the difficulty of detecting mosaic males because mosaicism can be detected to $\sim 10 \%$. Laboratories using TRP PCR are encouraged to define the sensitivity of their assay using DNA with a normal FMR1 allele titrated with serial dilutions of full-mutation FMR1 DNA.

FX 3.2.2.10.5: Methylation PCR methods. Several methods besides Southern blot analysis have been described to determine methylation. Methylation-specific PCR involves 


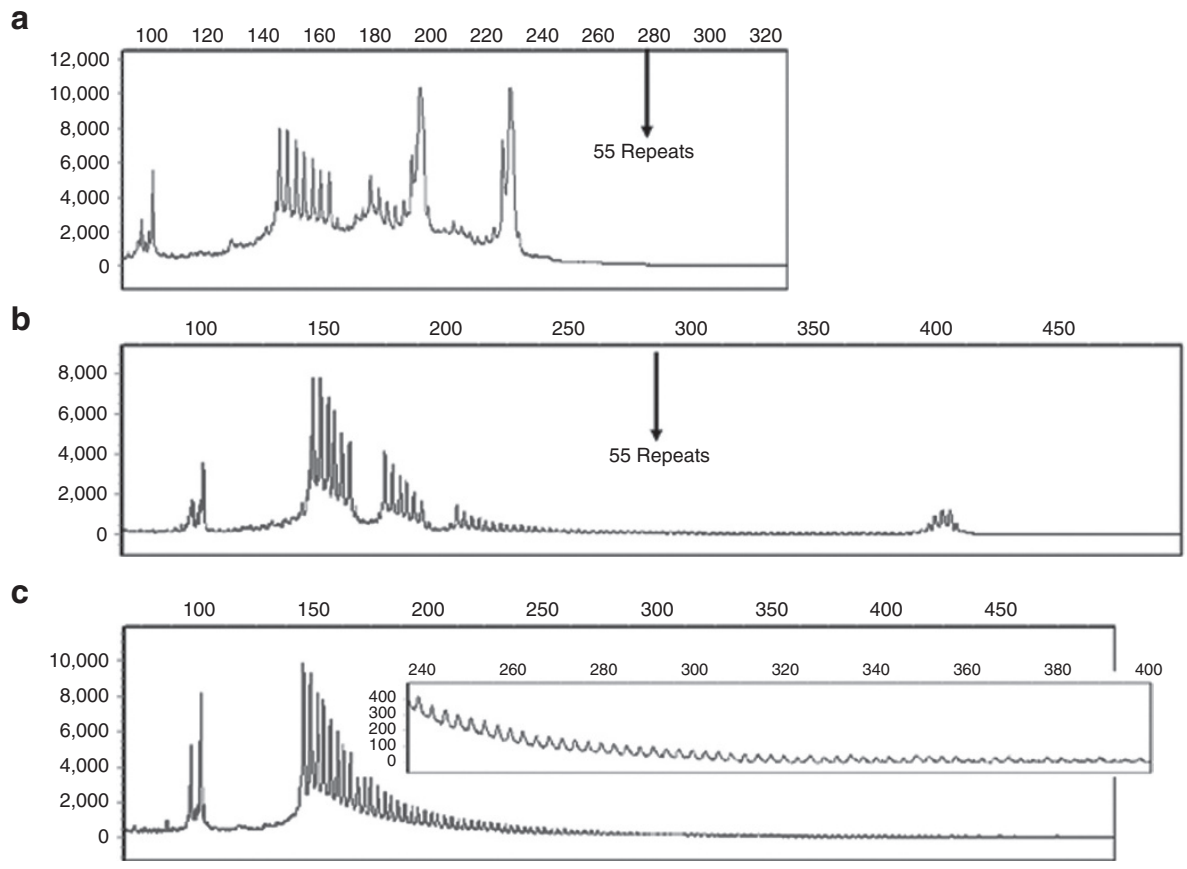

Figure 2 TRP PCR using a two-primer system. (a) Female with 20 and 31 CGG repeats. (b) Male with 103 CGG repeats. (c) Male with size mosaicism from $\sim 140$ to 800 CGG repeats (inset: reduced $y$-axis to better visualize baseline). TRP PCR, triplet repeat-primed PCR.

the differential treatment of DNA with methylation-specific restriction enzymes followed by allele-specific PCR and resolution of the PCR products with CE. ${ }^{90,91}$ This method not only determines methylation status but also FMR1 allele size up to 250 repeats. However, to accurately size alleles $>250$ repeats, Southern blot analysis is needed.

FX 3.2.2.11: Other methods. Multiplexed ligation probe amplification has been described to identify males with methylated fragile $\mathrm{X}$ alleles. ${ }^{92}$ In this method, sequencespecific probes are hybridized to methylated and unmethylated alleles. Probes are simultaneously ligated and digested with a methylation-sensitive restriction endonuclease. A universal PCR primer set will amplify only probes that are ligated and undigested, indicating methylated alleles.

Real-time PCR has also been described with TaqMan chemistry and by melt-curve analysis, using methylation-specific PCR. TaqMan chemistry amplifies separately methylated and unmethylated specific alleles and provides a ratio based on amplification cycle thresholds. ${ }^{33}$ Using melt analysis, methylated and unmethylated alleles are amplified simultaneously but due to differences of GC content can be resolved by differences in melting temperature between methylated and unmethylated alleles. ${ }^{93}$ These methods have high analytical sensitivity and specificity for detecting methylation in males but are less sensitive and specific in females.

\section{FX 3.3: Interpretations}

FX 3.3.1: Example reports are included in the Supplementary Appendix online. In addition to the items described in the current general ACMG Standards and Guidelines for Clinical Genetics Laboratories (http://www.acmg.net/StaticContent/
SGs/Section_G_2010.pdf), the following elements should be included in the report:

FX 3.3.1.1: State whether the method used was PCR, Southern blot analysis, or both. If Southern blot analysis, state the restriction enzymes and probes used. If PCR, describe the PCR method used (e.g., TRP PCR) and method used for separation and detection (e.g., CE).

$F X$ 3.3.1.2: State the definitions used for normal, intermediate (gray-zone, borderline, inconclusive), premutation, and full mutation.

FX 3.3.1.2.1: Note that it is not necessarily obvious that the borderline category refers to the border between normal and premutation and not to the border between premutation and full mutation. Similarly, note that the term instability, which is often used with regard to borderline alleles to describe minor intergenerational or mitotic changes, may unintentionally suggest a risk of having an affected child or personal late-onset symptoms.

FX 3.3.1.3: Classify the patient's result using the defined categories and Human Genome Variation Society nomenclature (refer to section 2.9.4). Common nomenclature can be included for clarity. The term size mosaic should be used for alleles that have significant subpopulations in both the premutation and full mutation range.

FX 3.3.1.4: All positive results should state that genetic counseling is recommended and testing is available for at-risk family members.

FX 3.3.2: The following descriptive elements may appear, with caution:

FX 3.3.2.1: The size of the alleles may be reported and could be of clinical use for premutation carriers. The premutation allele 

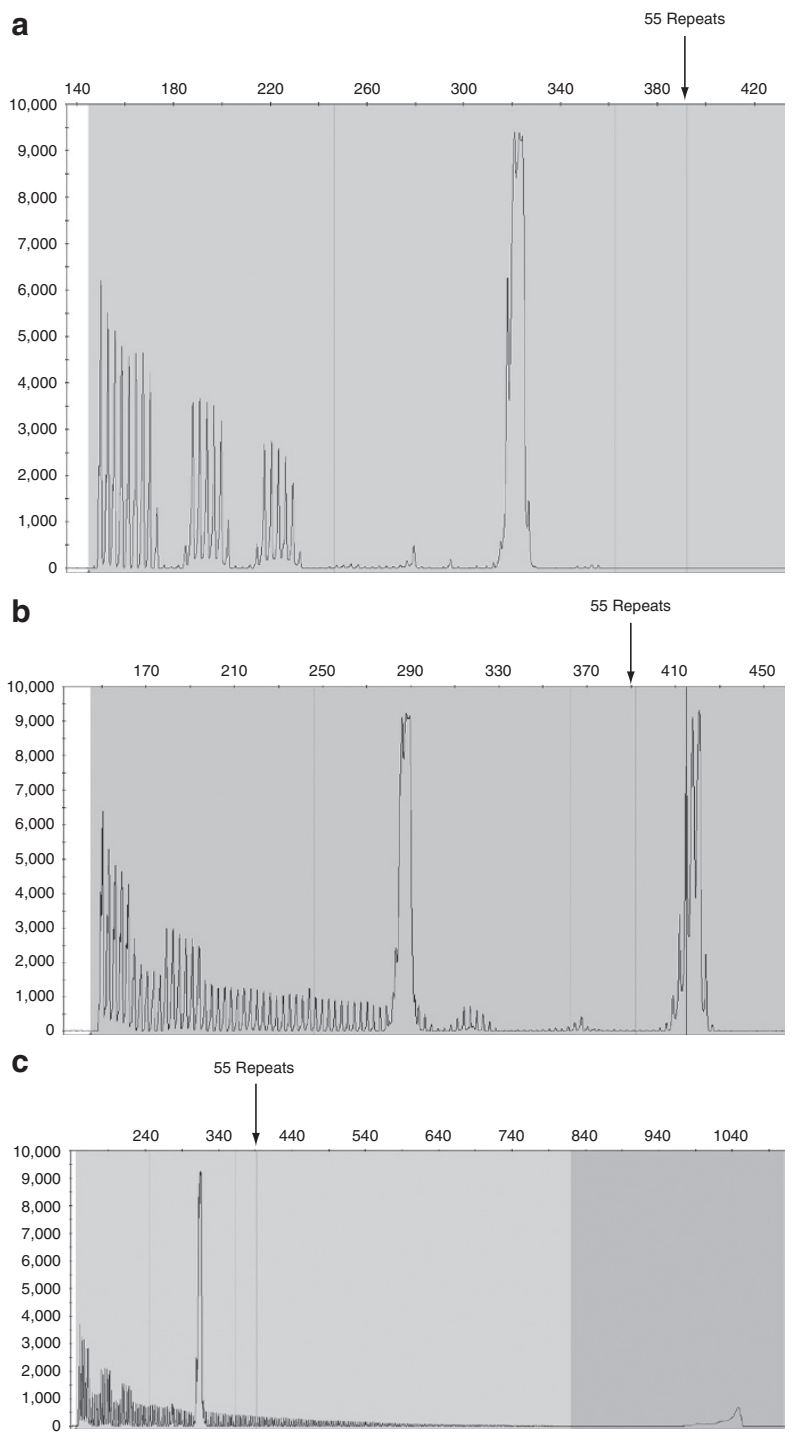

Figure 3 TRP PCR using a three-primer system. (a) Male with 32 CCG repeats. (b) Female with 20 and 64 CGG repeats. (c) Female with 29 and >200 CGG repeats. TRP PCR, triplet repeat-primed PCR.

size may be used for risk assessment in determining the chance of expansion in the offspring of carriers and also in determining the chance of FXTAS or FXPOI. If so, the precision used in quoting the size must be supportable by the precision of the size marker used, the sharpness of the bands or peaks, degree of stutter, and so on. It may be appropriate to state a range or use qualifying terms such as "approximately." Descriptions such as "positive for an allele with 55-200 repeats" are ambiguous and should not be included in a laboratory report.

It has been the intent of the CAP/ACMG Biochemical and Molecular Genetics Resource Committee to standardize the accuracy of CGG-repeat quantitation. The acceptable range for sizing CGG repeats is based on the analysis of CAP/ACMG proficiency testing survey results for fragile $\mathrm{X}$. Acknowledging the technical limitations of size analysis, the ACMG supports the following acceptable ranges for FMR1 clinical testing and/or as
ACMG STANDARDS AND GUIDELINES

grading criteria for the CAP/ACMG proficiency testing survey: consensus size \pm 5 repeats for alleles with $<55$ repeats; consensus size \pm 10 repeats for alleles with $56-100$ repeats; and consensus size \pm 2 SDs for alleles with $>100$ repeats.

FX 3.3.2.2: Description of methylation may be provided. The two kinds of methylation must be clearly distinguished: methylation due to X-inactivation and hypermethylation of full mutations. The term methylation mosaic or incomplete methylation may be used if not all molecules in a full mutation are hypermethylated.

FX 3.3.3: The following helpful points on alternative diagnoses may be included:

FX 3.3.3.1: There are rare forms of FMRP deficiency not caused by CGG expansion, which may not be detected by this test.

FX 3.3.3.2: Intellectual disability associated with other fragile $\mathrm{X}$ sites, in particular FRAXE, or other gene mutations will not be detected with this test.

$F X$ 3.3.3.3: DNA analysis for fragile $\mathrm{X}$ syndrome should be performed as part of a comprehensive genetic evaluation that includes routine cytogenetic analysis ${ }^{51}$ and more recently chromosomal microarray analysis as recommended by ACMG. ${ }^{94,95}$

FX 3.3.4: Comments on phenotype, if included, should be abstract rather than case specific. The following concepts apply:

FX 3.3.4.1: All males with full mutations have fragile $\mathrm{X}$ syndrome to some degree. The severity cannot be predicted from the size of the full mutation, but if premutations are also present or if the majority of the full-mutation molecules are unmethylated, the phenotype may be less severe.

$F X$ 3.3.4.2: Females with full mutations exhibit a wide spectrum of phenotypes. They may be as severely affected as a male with an expanded fragile $\mathrm{X}$ allele (which is itself a range of phenotypes). Females with full mutations may also exhibit very mild learning disabilities or have no detectable deficits. The severity cannot be predicted from the size of the full mutation, nor can it be predicted from the pattern of X-inactivation.

FX 3.3.4.3: Individuals with premutations should not be interpreted as unaffected carriers. Females who carry a premutation are at risk for FXPOI and FXTAS. Males with the premutation are at risk for FXTAS. If an individual referred for diagnostic testing due to intellectual disability, autism, or learning disability is found to carry a premutation, no association can be stated at this point in time. It should be considered as a coincident finding unless FMRP deficiency or mosaicism for a full mutation is detected.

$F X$ 3.3.4.4: Individuals with intermediate alleles should be interpreted as unaffected. Even more so than a premutation, an intermediate allele is considered a coincidence when found in an individual referred for diagnostic testing due to intellectual disability, learning disability, or autism. FMRP deficiency or mosaicism for a full mutation can be investigated by methylation-sensitive Southern blot analysis but with less 
likelihood of success because intermediate alleles are common in the general population.

FX 3.3.5: Comments on reproductive risk, if included, should be abstract rather than case specific. The following concepts apply:

FX 3.3.5.1: All affected males and the overwhelming majority of affected females inherit their mutations from their mothers. The mothers carry either a premutation or full mutation.

FX 3.3.5.2: Women with full mutations have a theoretical $50 \%$ chance of passing on the full mutation with each pregnancy.

FX 3.3.5.3: Women with premutations have a theoretical $50 \%$ chance of passing on the fragile $\mathrm{X}$ mutation with each pregnancy. If it is passed on, the chance the allele will increase to a full mutation depends on its size in the mother. Probabilities range from 3\% for maternal alleles with CGG repeats from 55 to 59 (1/23 transmissions) to $100 \%$ for maternal alleles with 90 CGGs and above. ${ }^{67}$ The smallest allele known to expand to the full mutation is 56 repeats. ${ }^{63}$ Laboratories should be familiar with publications on this topic, ${ }^{65-67,78,96}$ including any current publications.

FX 3.3.5.4: Men with premutations will almost always pass premutations to all of their daughters. An extremely rare phenomenon involves unaffected males with premutations who have had affected daughters, apparently by gonadal mosaicism for full mutations. ${ }^{97-99}$ The sons of men with premutations are not at risk for developing the fragile X syndrome or FXTAS.

FX 3.3.5.5: To date, there have been no reports of male or female carriers of intermediate alleles having offspring with an FMR1 allele in the full mutation range. Instability may be identified if the allele can be traced through the family to a known full mutation or unambiguous premutation. In the absence of such a connection, it may be possible to show meiotic instability or a specific repeat sequence pattern (absence of AGG interruptions) that is at higher risk for instability. Testing for AGG status is available, although the clinical usefulness of this information is not known at this time.

\section{FX 4: ALTERNATIVE TESTING METHODS FX 4.1: Cytogenetic analysis}

Testing for the fragile site FRAXA at Xq27 is no longer an acceptable diagnostic method. Clinical and analytical specificity and sensitivity are both insufficient.

\section{FX 4.2: Protein analysis}

Immunohistochemical staining for FMRP is a valid diagnostic method in lymphocytes. ${ }^{100}$ Willemsen et al..$^{56}$ demonstrated that staining for the FMRP protein in chorionic villus samples could be used as an alternative prenatal diagnostic method for detection of full mutations in male fetuses. The situation is more complicated in female fetuses for which some chorionic villi may be completely positive and others from the same sample may be completely negative for FMRP staining. The authors' data shed light on the timing of X-inactivation in chorionic villus cells of the female fetus. The diagnostic application of this method is not recommended at this time for the prenatal diagnosis of females carrying FMR1 full mutations.

\section{FX 5: POLICY STATEMENTS}

\section{FX 5.1}

The American College of Medical Genetics and Genomics issued a policy statement titled "Fragile X Syndrome: Diagnosis and Carrier Testing" in 1994 (Am J Med Genet 53:380-381), which was updated in October 2005 (Genet Med 7:584-587). This document is also available online at http://www.acmg.net/ resources/policy-list.asp. These Standards and Guidelines are in general agreement with that statement.

\section{FX 5.2}

In 2010, the American College of Obstetricians and Gynecologists issued a Committee Opinion, No. 469, on carrier screening for fragile $\mathrm{X}$ syndrome. These Standards and Guidelines are in general agreement with that opinion.

\section{SUPPLEMENTARY MATERIAL}

Supplementary material is linked to the online version of the paper at http://www.nature.com/gim

\section{DISCLOSURE}

The authors direct laboratories that offer clinical molecular genetic testing for fragile $\mathrm{X}$ syndrome.

\section{REFERENCES}

1. Tassone F, Hagerman RJ, Taylor AK, et al. Clinical involvement and protein expression in individuals with the FMR1 premutation. Am J Med Genet 2000;91:144-152.

2. Hundscheid RD, Smits AP, Thomas CM, Kiemeney LA, Braat DD. Female carriers of fragile $X$ premutations have no increased risk for additional diseases other than premature ovarian failure. Am J Med Genet A 2003;117A:6-9.

3. Marozzi A, Vegetti W, Manfredini E, et al. Association between idiopathic premature ovarian failure and fragile $X$ premutation. Hum Reprod 2000;15:197-202.

4. Murray A, Ennis S, Morton N. No evidence for parent of origin influencing premature ovarian failure in fragile X premutation carriers. Am J Hum Genet 2000;67:253-254; author reply 256.

5. Murray A. Premature ovarian failure and the FMR1 gene. Semin Reprod Med 2000;18:59-66.

6. Sherman SL. Premature ovarian failure in the fragile X syndrome. Am J Med Genet 2000;97:189-194.

7. Wittenberger MD, Hagerman RJ, Sherman SL, et al. The FMR1 premutation and reproduction. Fertil Steril 2007;87:456-465.

8. Bennett CE, Conway GS, Macpherson JN, Jacobs PA, Murray A. Intermediate sized CGG repeats are not a common cause of premature ovarian failure. Hum Reprod 2010;25(5):1335-1338.

9. Spath MA, Feuth TB, Smits AP, et al. Predictors and risk model development for menopausal age in fragile X premutation carriers. Genet Med 2011;13:643-650.

10. Jacquemont S, Hagerman RJ, Leehey MA, et al. Penetrance of the fragile $\mathrm{X}$-associated tremor/ataxia syndrome in a premutation carrier population. JAMA 2004;291:460-469.

11. Hagerman PJ, Greco CM, Hagerman RJ. A cerebellar tremor/ataxia syndrome among fragile X premutation carriers. Cytogenet Genome Res 2003;100: 206-212.

12. Jacquemont S, Hagerman RJ, Leehey $M$, et al. Fragile X premutation tremor/ ataxia syndrome: molecular, clinical, and neuroimaging correlates. Am J Hum Genet 2003;72:869-878.

13. Rogers C, Partington MW, Turner GM. Tremor, ataxia and dementia in older men may indicate a carrier of the fragile X syndrome. Clin Genet 2003;64: 54-56. 
14. Tassone F, Hagerman RJ, Garcia-Arocena D, Khandjian EW, Greco CM, Hagerman PJ. Intranuclear inclusions in neural cells with premutation alleles in fragile X associated tremor/ataxia syndrome. J Med Genet 2004;41:e43.

15. Hagerman RJ, Leavitt BR, Farzin F, et al. Fragile-X-associated tremor/ataxia syndrome (FXTAS) in females with the FMR1 premutation. Am J Hum Genet 2004;74:1051-1056.

16. Rodriguez-Revenga L, Madrigal I, Pagonabarraga J, et al. Penetrance of FMR1 premutation associated pathologies in fragile $X$ syndrome families. Eur J Hum Genet 2009:17:1359-1362.

17. Tassone F, Adams J, Berry-Kravis EM, et al. CGG repeat length correlates with age of onset of motor signs of the fragile $\mathrm{X}$-associated tremor/ataxia syndrome (FXTAS). Am J Med Genet B Neuropsychiatr Genet 2007;144B:566-569.

18. Leehey MA, Berry-Kravis E, Goetz CG, et al. FMR1 CGG repeat length predicts motor dysfunction in premutation carriers. Neurology 2008;70(16 Pt 2):13971402.

19. Berry-Kravis E, Abrams L, Coffey SM, et al. Fragile X-associated tremor/ataxia syndrome: clinical features, genetics and testing guidelines. Mov Disord 2007;22(14):2018-2030.

20. O'Donnell WT, Warren ST. A decade of molecular studies of fragile X syndrome. Annu Rev Neurosci 2002;25:315-338.

21. Li Z, Zhang Y, Ku L, Wilkinson KD, Warren ST, Feng Y. The fragile X mental retardation protein inhibits translation via interacting with mRNA. Nucleic Acids Res 2001;29:2276-2283.

22. Hinton VJ, Brown WT, Wisniewski K, Rudelli RD. Analysis of neocortex in three males with the fragile X syndrome. Am J Med Genet 1991;41:289-294.

23. Irwin SA, Galvez R, Greenough WT. Dendritic spine structural anomalies in fragile-X mental retardation syndrome. Cereb Cortex 2000;10:1038-1044.

24. Feng $Y$, Gutekunst $C A$, Eberhart DE, Yi H, Warren ST, Hersch SM. Fragile X mental retardation protein: nucleocytoplasmic shuttling and association with somatodendritic ribosomes. J Neurosci 1997;17:1539-1547.

25. Bardoni B, Mandel JL. Advances in understanding of fragile X pathogenesis and FMRP function, and in identification of $X$ linked mental retardation genes. Curr Opin Genet Dev 2002;12:284-293.

26. Aschrafi A, Cunningham BA, Edelman GM, Vanderklish PW. The fragile $X$ mental retardation protein and group I metabotropic glutamate receptors regulate levels of mRNA granules in brain. Proc Natl Acad Sci USA 2005;102:2180-2185.

27. Tassone F, Hagerman RJ, Taylor AK, Gane LW, Godfrey TE, Hagerman PJ. Elevated levels of FMR1 mRNA in carrier males: a new mechanism of involvement in the fragile-X syndrome. Am J Hum Genet 2000;66:6-15.

28. Kenneson A, Zhang F, Hagedorn CH, Warren ST. Reduced FMRP and increased FMR1 transcription is proportionally associated with CGG repeat number in intermediate-length and premutation carriers. Hum Mol Genet 2001;10:14491454.

29. Tassone F, Hagerman RJ, Chamberlain WD, Hagerman PJ. Transcription of the FMR1 gene in individuals with fragile X syndrome. Am J Med Genet 2000:97:195-203.

30. Beilina A, Tassone F, Schwartz PH, Sahota P, Hagerman PJ. Redistribution of transcription start sites within the FMR1 promoter region with expansion of the downstream CGG-repeat element. Hum Mol Genet 2004;13:543-549.

31. Galloway JN, Nelson DL. Evidence for RNA-mediated toxicity in the fragile X-associated tremor/ataxia syndrome. Future Neurol 2009;4:785.

32. Hill MK, Archibald AD, Cohen J, Metcalfe SA. A systematic review of population screening for fragile X syndrome. Genet Med 2010;12:396-410.

33. Coffee $B$, Keith $K$, Albizua I, et al. Incidence of fragile $X$ syndrome by newborn screening for methylated FMR1 DNA. Am J Hum Genet 2009;85:503-514.

34. Lévesque S, Dombrowski C, Morel ML, et al. Screening and instability of FMR1 alleles in a prospective sample of 24,449 mother-newborn pairs from the general population. Clin Genet 2009;76:511-523.

35. Peprah E. Fragile X syndrome: the FMR1 CGG repeat distribution among world populations. Ann Hum Genet 2012;76:178-191.

36. Crawford DC, Acuña JM, Sherman SL. FMR1 and the fragile X syndrome: human genome epidemiology review. Genet Med 2001;3:359-371.

37. Crawford DC, Meadows KL, Newman JL, et al. Prevalence of the fragile $X$ syndrome in African-Americans. Am J Med Genet 2002;110:226-233.

38. Elbaz A, Suédois J, Duquesnoy M, Beldjord C, Berchel C, Mérault G. Prevalence of fragile-X syndrome and FRAXE among children with intellectual disability in a Caribbean island, Guadeloupe, French West Indies. J Intellect Disabil Res 1998:42(Pt 1):81-89.

39. Falik-Zaccai TC, Shachak E, Yalon M, et al. Predisposition to the fragile $X$ syndrome in Jews of Tunisian descent is due to the absence of AGG interruptions on a rare Mediterranean haplotype. Am J Hum Genet 1997;60:103-112.
40. Toledano-Alhadef H, Basel-Vanagaite L, Magal N, et al. Fragile-X carrier screening and the prevalence of premutation and full-mutation carriers in Israel. Am J Hum Genet 2001;69:351-360.

41. Tzeng CC, Tsai LP, Hwu WL, et al. Prevalence of the FMR1 mutation in Taiwan assessed by large-scale screening of newborn boys and analysis of DXS548FXAC1 haplotype. Am J Med Genet 2005;A133:37-43.

42. Cronister A, DiMaio M, Mahoney MJ, Donnenfeld AE, Hallam S. Fragile X syndrome carrier screening in the prenatal genetic counseling setting. Genet Med 2005;7:246-250.

43. Strom CM, Crossley B, Redman JB, et al. Molecular testing for Fragile $X$ Syndrome: lessons learned from 119,232 tests performed in a clinical laboratory. Genet Med 2007;9:46-51.

44. Rousseau F, Rouillard P, Morel ML, Khandjian EW, Morgan K. Prevalence of carriers of premutation-size alleles of the FMRI gene-and implications for the population genetics of the fragile X syndrome. Am J Hum Genet 1995;57:1006-1018.

45. Dombrowski C, Lévesque S, Morel ML, Rouillard P, Morgan K, Rousseau F. Premutation and intermediate-size FMR1 alleles in 10572 males from the general population: loss of an AGG interruption is a late event in the generation of fragile X syndrome alleles. Hum Mol Genet 2002;11:371-378.

46. Berkenstadt M, Ries-Levavi L, Cuckle H, Peleg L, Barkai G. Preconceptional and prenatal screening for fragile $X$ syndrome: experience with 40,000 tests. Prenat Diagn 2007;27:991-994.

47. Pesso R, Berkenstadt $M$, Cuckle $H$, et al. Screening for fragile $X$ syndrome in women of reproductive age. Prenat Diagn 2000;20:611-614.

48. Grasso M, Berti C, Ricci V, et al. Assessment of Fragile X premutation incidence in an Italian population: lessons for population screening. Paper presented at the 10th International Workshop on Fragile X and X-linked Mental Retardation. Frascati, Italy, 19-22 September 2001.

49. Sullivan SD, Welt C, Sherman S. FMR1 and the continuum of primary ovarian insufficiency. Semin Reprod Med 2011;29:299-307.

50. Cellini E, Forleo P, Ginestroni A, et al. Fragile X premutation with atypical symptoms at onset. Arch Neurol 2006;63:1135-1138.

51. Sherman S, Pletcher BA, Driscoll DA. Fragile X syndrome: diagnostic and carrier testing. Genet Med 2005;7:584-587.

52. The American College of Obstetricians and Gynecologists Committee Opinion. Carrier screening for fragile X syndrome. Obstet Gynecol 2010;116:10081010

53. Kronquist KE, Sherman SL, Spector EB. Clinical significance of tri-nucleotide repeats in Fragile $\mathrm{X}$ testing: a clarification of American College of Medical Genetics guidelines. Genet Med 2008;10:845-847.

54. Hagerman RJ, Jackson C, Amiri K, Silverman AC, O'Connor R, Sobesky W. Girls with fragile $X$ syndrome: physical and neurocognitive status and outcome. Pediatrics 1992;89:395-400

55. de Vries BB, Wiegers AM, Smits AP, et al. Mental status of females with an FMR1 gene full mutation. Am J Hum Genet 1996;58:1025-1032.

56. Willemsen R, Bontekoe CJ, Severijnen LA, Oostra BA. Timing of the absence of FMR1 expression in full mutation chorionic villi. Hum Genet 2002;110:601605.

57. Maddalena A, Hicks BD, Spence WC, Levinson G, Howard-Peebles PN. Prenatal diagnosis in known fragile X carriers. Am J Med Genet 1994;51:490-496.

58. ACMG Standards and Guidelines for Clinical Genetics Labs. http://www. acmg.net/AM/Template.cfm?Section=Laboratory_Standards_and Guidelines\&Template=/CM/HTMLDisplay.. fm\&ContentID $=7439$. Accessed $2 \overline{9}$ March 2013.

59. College of American Pathologists. Molecular pathology checklist, item MOL.49630. Standard nomenclature. http://www.cap.org. Accessed 29 March 2013

60. Human Genome Variation Society. Nomenclature for the description of sequence variants. http://www. hgvs.org/mutnomen. Accessed 29 March 2013.

61. Yrigollen CM, Durbin-Johnson B, Gane L, et al. AGG interruptions within the maternal FMR1 gene reduce the risk of offspring with fragile $X$ syndrome. Genet Med 2012;14:729-736.

62. Hall D, Tassone F, Klepitskaya O, Leehey M. Fragile X-associated tremor ataxia syndrome in FMR1 gray zone allele carriers. Mov Disord 2012;27:296-300.

63. Fernandez-Carvajal I, Lopez Posadas B, Pan R, Raske C, Hagerman PJ, Tassone F. Expansion of an FMR1 grey-zone allele to a full mutation in two generations. $J$ Mol Diagn 2009;11:306-310.

64. Hunter JE, Abramowitz A, Rusin M, Sherman SL. Is there evidence for neuropsychological and neurobehavioral phenotypes among adults without FXTAS who carry the FMR1 premutation? A review of current literature. Genet Med 2009;11:79-89. 
65. Nolin SL, Brown WT, Glicksman A, et al. Expansion of the fragile X CGG repeat in females with premutation or intermediate alleles. Am J Hum Genet 2003;72:454-464.

66. Kallinen J, Heinonen S, Mannermaa A, Ryynänen M. Prenatal diagnosis of fragile $X$ syndrome and the risk of expansion of a premutation. Clin Genet 2000;58:111-115.

67. Nolin SL, Lewis FA 3rd, Ye LL, et al. Familial transmission of the FMR1 CGG repeat. Am J Hum Genet 1996;59:1252-1261.

68. Hagerman RJ, Hull CE, Safanda JF, et al. High functioning fragile X males: demonstration of an unmethylated fully expanded FMR-1 mutation associated with protein expression. Am J Med Genet 1994;51:298-308.

69. Rousseau F, Robb $L$, Rouillard P, Der Kaloustian VM. No mental retardation in a man with 40\% abnormal methylation at the FMR-1 locus and transmission of sperm cell mutations as premutations. Hum Mol Genet 1994;3:927-930.

70. Schmucker B, Seidel J. Mosaicism for a full mutation and a normal size allele in two fragile X males. Am J Med Genet 1999;84:221-225.

71. Smeets HJ, Smits AP, Verheij CE, et al. Normal phenotype in two brothers with a full FMR1 mutation. Hum Mol Genet 1995;4:2103-2108.

72. Rousseau F, Heitz D, Biancalana V, et al. Direct diagnosis by DNA analysis of the fragile X syndrome of mental retardation. N Engl J Med 1991;325:1673-1681.

73. Verkerk AJ, Pieretti M, Sutcliffe JS, et al. Identification of a gene (FMR-1) containing a CGG repeat coincident with a breakpoint cluster region exhibiting length variation in fragile X syndrome. Cell 1991;65:905-914.

74. Nakahori Y, Knight SJ, Holland J, et al. Molecular heterogeneity of the fragile $X$ syndrome. Nucleic Acids Res 1991;19:4355-4359.

75. Yu S, Pritchard M, Kremer E, et al. Fragile X genotype characterized by an unstable region of DNA. Science 1991;252:1179-1181.

76. Centers for Disease Control and Prevention. Genetic Testing Reference Materials Coordination Program (GeT-RM). http://wwwn.cdc.gov/dls/genetics/ RMMaterials. Accessed 29 March 2013.

77. Coriell Institute for Medical Research. Coriell cell repositories. http://www.ccr. coriell.org. Accessed 29 March 2013.

78. Fu YH, Kuhl DP, Pizzuti $A$, et al. Variation of the CGG repeat at the fragile $X$ site results in genetic instability: resolution of the Sherman paradox. Cell 1991;67:1047-1058.

79. Yu S, Mulley J, Loesch D, et al. Fragile-X syndrome: unique genetics of the heritable unstable element. Am J Hum Genet 1992;50:968-980.

80. Erster SH, Brown WT, Goonewardena P, Dobkin CS, Jenkins EC, Pergolizzi RG. Polymerase chain reaction analysis of fragile X mutations. Hum Genet 1992;90:55-61.

81. Brown WT, Houck GE Jr, Jeziorowska A, et al. Rapid fragile X carrier screening and prenatal diagnosis using a nonradioactive PCR test. JAMA 1993;270:15691575

82. de Graaff E, Rouillard P, Willems PJ, Smits AP, Rousseau F, Oostra BA. Hotspot for deletions in the $C G G$ repeat region of FMR1 in fragile X patients. Hum Mol Genet 1995;4:45-49.

83. Das S, Kubota T, Song M, et al. Methylation analysis of the fragile X syndrome by PCR. Genet Test 1997;1:151-155.

84. Panagopoulos I, Lassen C, Kristoffersson U, Aman P. A methylation PCR approach for detection of fragile X syndrome. Hum Mutat 1999;14:71-79.

85. Tassone F, Pan R, Amiri K, Taylor AK, Hagerman PJ. A rapid polymerase chain reaction-based screening method for identification of all expanded alleles of the fragile X (FMR1) gene in newborn and high-risk populations. J Mol Diagn 2008; 10:43-49.
86. Chen L, Hadd A, Sah S, et al. An information-rich CGG repeat primed PCR that detects the full range of fragile $X$ expanded alleles and minimizes the need for southern blot analysis. J Mol Diagn 2010;12:589-600.

87. Hantash FM, Goos DG, Tsao D, et al. Qualitative assessment of FMR1 (CGG)n triplet repeat status in normal, intermediate, premutation, full mutation, and mosaic carriers in both sexes: implications for fragile X syndrome carrier and newborn screening. Genet Med 2010;12: 162-173.

88. Lyon $\mathrm{E}$, Laver $\mathrm{T}$, Yu $\mathrm{P}$, et al. A simple, high-throughput assay for Fragile $\mathrm{X}$ expanded alleles using triple repeat primed PCR and capillary electrophoresis. J Mol Diagn 2010;12:505-511.

89. Nahhas FA, Monroe TJ, Prior TW, et al. Evaluation of the human fragile $X$ mental retardation 1 polymerase chain reaction reagents to amplify the FMR1 gene: testing in a clinical diagnostic laboratory. Genet Test Mol Biomarkers 2012;16:187-192.

90. Zhou Y, Law HY, Boehm CD, et al. Robust fragile $X$ (CGG)n genotype classification using a methylation specific triple PCR assay. J Med Genet 2004;41:e45

91. Chen L, Hadd AG, Sah S, et al. High-resolution methylation polymerase chain reaction for fragile $X$ analysis: evidence for novel FMR1 methylation patterns undetected in Southern blot analyses. Genet Med 2011;13:528-538.

92. Nygren AO, Lens SI, Carvalho R. Methylation-specific multiplex ligationdependent probe amplification enables a rapid and reliable distinction between male FMR1 premutation and full-mutation alleles. J Mol Diagn 2008;10:496501.

93. Elias MH, Ankathil R, Salmi AR, Sudhikaran W, Limprasert P, Zilfalil BA. A new method for FMR1 gene methylation screening by multiplex methylation-specific real-time polymerase chain reaction. Genet Test Mol Biomarkers 2011;15:387393.

94. Shaffer LG. American College of Medical Genetics guideline on the cytogenetic evaluation of the individual with developmental delay or mental retardation. Genet Med 2005;7:650-654.

95. Schaefer GB, Mendelsohn NJ. Clinical genetics evaluation in identifying the etiology of autism spectrum disorders: 2013 guideline revisions. Genet Med 2013;15:399-407.

96. Heitz D, Devys D, Imbert G, Kretz C, Mandel JL. Inheritance of the fragile X syndrome: size of the fragile $\mathrm{X}$ premutation is a major determinant of the transition to full mutation. J Med Genet 1992;29:794-801.

97. Patsalis PC, Sismani C, Stylianou S, et al. Genetic variation and intergenerational FMR1 CGG-repeat stability in 100 unrelated three-generation families from the normal population. Am J Med Genet 1999;84:217-220

98. Zeesman S, Zwaigenbaum L, Whelan DT, Hagerman RJ, Tassone F, Taylor SA. Paternal transmission of fragile X syndrome. Am J Med Genet A 2004;129A:184-189.

99. Rifé $\mathrm{M}$, Badenas $\mathrm{C}$, Quintó $\mathrm{L}$, et al. Analysis of $\mathrm{CGG}$ variation through 642 meioses in Fragile X families. Mol Hum Reprod 2004; 10:773-776.

100. Oostra BA, Willemsen R. Diagnostic tests for fragile X syndrome. Expert Rev Mol Diagn 2001;1:226-232.

101. Maddalena A, Richards CS, McGinnis MJ, et al.; Quality Assurance Subcommittee of the Laboratory Practice Committee. Technical standards and guidelines for fragile $X$ : the first of a series of disease-specific supplements to the Standards and Guidelines for Clinical Genetics Laboratories of the American College of Medical Genetics. Genet Med $2001 ; 3: 200-205$ 